Family Medicine and Community Health

\section{Progress towards using community context with clinical data in primary care}

To cite: Angier $\mathrm{H}$, Jacobs EA, Huguet N, et al. Progress towards using community context with clinical data in primary care. Fam Med Com Health 2018;7:e000028. doi:10.1136/fmch-2018-000028

Received 24 September 2018 Accepted 25 September 2018

Check for updates

(c) Author(s) (or their employer(s)) 2018. Re-use permitted under CC BY-NC. No commercial re-use. See rights and permissions. Published by BMJ.

${ }^{1}$ Oregon Health \& Science University, Portland, Oregon, USA ${ }^{2}$ University of Texas at Austin, Dell Medical School, Austin, Texas, USA

${ }^{3}$ University of WisconsinMadison, Madison, Wisconsin, USA

Correspondence to

Heather Angier;

angierh@ohsu.edu

\section{ABSTRACT}

Community-level factors have significant impacts on health. There is renewed enthusiasm for integrating these data with electronic health record (EHR) data for use in primary care to improve health equity in the USA. Thus, it is valuable to reflect on what has been published to date. Specifically, we comment on: (1) recommendations about combining community-level factors in EHRs for use in primary care; (2) examples of how these data have been combined and used; and (3) the impact of using combined data on healthcare, patient health and health equity. We found publications discussing the potential of combined data to inform clinical care, target interventions, track population health and spark community partnerships with the goal of reducing health disparities and improving health equity. Although there is great enthusiasm and potential for using these data to inform primary care, there is little evidence of improved healthcare, patient health or health equity.

\section{INTRODUCTION}

Neighbourhood and community factors have significant impacts on health. ${ }^{1-3}$ For example, neighbourhood deprivation, poverty, racial segregation, poor air quality and poor food availability have been associated with mortality, ${ }^{4}$ poor physical and mental health, ${ }^{5-8}$ poor healthcare access ${ }^{9} 10$ and less healthcare utilisation. ${ }^{11}$ Research has also mapped and highlighted geographical clustering of health, health behaviours and environmental issues by neighbourhood. ${ }^{12}$ The main goals of Healthy People 2020 are to reduce health disparities and achieve health equity by addressing the 'social, economic, and physical' barriers to health, ${ }^{13}$ and public health interventions and policies have aimed to improve neighbourhood conditions, and to develop food and physical activity environments that improve health. ${ }^{14}$ Despite this, most primary healthcare teams have not fully integrated new data technologies into their practice to increase and apply knowledge about neighbourhood and community factors.
The idea of integrating knowledge about a patient's environment and community to provide comprehensive care is not new ${ }^{15-17}$; however, little is known about whether primary care teams have access to this information or if they are using it routinely. Recent advancements in health information technology, especially electronic health records (EHRs) and the availability of electronic data, have increased the potential for integrating and meaningfully using these data in primary care. Currently, there are a large amount of geocoded, community-level data publicly available in the USA from a variety of sources such as the US Census Bureau, American Community Survey and the Centers for Disease Control and Prevention. ${ }^{18}$ Examples include: neighbourhood economic conditions, racial/ethnic segregation, and environmental exposures. Thus, there have been improvements in the data and the systems that enable primary care to use a patient's community context (ie, community-level factors) and to address community needs.

Several national organisations recommend tracking and addressing the community context of patients to improve equity and reduce health and healthcare disparities, including: the National Academy of Medicine (NAM; previously the Institute of Medicine), the American Academy of Pediatrics and the American Academy of Nursing. ${ }^{19-21}$ For example, one of the recommendations of the NAM is to collect and geocode patient addresses to understand the 'role of built and social environment on health behaviors and on disease onset and progression'. ${ }^{19}$

Given this renewed enthusiasm for using these data, it is valuable to reflect on what has been published about using community-level factors with EHR data in primary care settings. Here, we focus on the USA because community contextual data availability, social conditions, and the social and healthcare 
safety net are very different from other countries. Specifically, we comment on: (1) recommendations around combining community-level factors in EHRs and using this information in the primary care setting; (2) examples of how these data have been combined and used; and (3) the impact of using combined data on healthcare, patient health and health equity.

\section{What are the recommendations for adding a patient's} community-level factors to the EHR to inform primary care?

There are many ideas about the potential uses of linked publicly available community-level factors and EHR clinical data in primary care settings. Primary care clinicians and researchers suggest these data can be used to improve patient care by identifying where to target interventions, ${ }^{22-25}$ tracking population health ${ }^{26} 27$ and informing clinical care. ${ }^{18} 192324$ 27-29 Bazemore et al recommend the addition of community-level data, which they call 'community vital signs', to the EHR for clinicians to inform clinical decision-making, similar to the availability and use of biological vital signs like blood pressure and heart rate. In addition to using these data for point-of-care clinical decision-making, they suggest using community vital signs for panel management and assessing population health. ${ }^{18}$ They also describe the technical aspects of how their team plans to connect these community vital signs to EHR data within a clinical data research network setting. ${ }^{18}$ They appended information on the built environment, environmental exposures and neighbourhood sociodemographics to a large network of geocoded patient addresses.

Hughes et al add that mapping 'hot' (high-odds) and 'cold' (low-odds) spots for different health conditions and issues can help primary care providers and clinics create targeted interventions. ${ }^{23}$ NAM also suggests these data can be used for diagnosis and treatment, and population health measurement. For example, NAM asserts that clinicians could use contextual information to tailor treatment plans. ${ }^{19}$ Remington and Wadland describe a bidirectional benefit of combining community-level factors and EHRs: (1) adding community-level factors to EHRs can be helpful for patient care, and (2) adding clinical data from EHRs to community-level data could enhance public health surveillance systems. ${ }^{27}$

Simpson and Novak posit that the connection between community-level factors and EHR data could assist providers with understanding patient context and delivering tailored care at all times, but that it could be particularly important when a natural disaster occurs. They interviewed patients and found many had a difficult time with self-care for chronic disease when their management routines were disrupted during a flood. Thus, alerts and reminders to patients living in an area affected by natural disaster with a diagnosis of diabetes could help them manage their chronic disease during this difficult time. ${ }^{30}$ In addition, there are several examples of using community-level factors with EHR data to identify where patients live and seek care in order to locate or relocate healthcare services. ${ }^{22}$ 31-33

Others suggest that linked community-level and EHR data can be used in primary care to promote community referrals and partnerships, and clinician advocacy for their patient population. ${ }^{20}$ For example, community-level factors could be used in primary care to refer patients for focused outreach, including: case management, transportation support and community resources. ${ }^{24}$ Use of these data to understand challenges in patients' community context can help clinicians and systems identify barriers to health and recovery, and to address these 'upstream' determinants of health in the community. ${ }^{34}$ In addition, the Institute of Health Equity identified actions for healthcare providers to use a patient's community contextual information to: see the patient in a broader perspective, work in partnership with community organisations and advocate for health equity. ${ }^{3536}$ The Council on Community Pediatrics also recommends advocacy as a way for clinicians to improve children's health equity and decrease child health disparities. Clinicians can use their influence to advocate for healthy environments, health equity initiatives and policies that support positive parenting practices. ${ }^{20}$

Efforts to combine community-level factors and EHR clinical data also have the potential to catalyse partnerships between primary care and community organisations. For example, Henize $a t a l^{37}$ developed a conceptual road map for how primary care providers and clinics can help patients through community partnerships with the following steps. First, primary care providers and clinics should assess the needs of their patients and prioritise them in order of importance. Second, they should build collaborations with community partners to develop a plan of action based on the needs assessment. Lastly, the partnership should be operationalised within the healthcare setting through training around community determinants of health, development of EHR tools to track data and partnerships, and strategies to allow patients to connect with community partners from within the clinic.

Another potential use for connecting community-level data to EHRs is to risk-adjust quality indicators so that clinicians are not financially penalised for providing healthcare to patients living in neighbourhoods with high deprivation scores. ${ }^{38}{ }^{39}$ Nelson et al found that mortality was higher for those living in neighbourhoods with low socioeconomic status, independent of individual characteristics and pointed out the need to risk adjust health outcome payments by neighbourhood context in order to adequately compensate providers serving people from disadvantaged neighbourhoods. ${ }^{4}$

Overall, access to patients' community-level factors within EHRs has the potential to have a positive impact on health at the patient, community, provider, health planning and system levels. With targeted interventions, population health measurement and tailored treatment 
plans, contextual information about patients could help narrow disparities and improve health equity.

\section{How have community-level factors been successfully linked to EHR data and used in primary care?}

Community-level factors and clinical EHR data were combined to identify areas with high uninsurance rates to identify where an outreach programme could be implemented to increase health insurance coverage for patients seen in a practice-based research network of safety net clinics. ${ }^{40}$ Geraghty et al, demonstrated how community-level and EHR data can be used together to understand and improve chronic disease management for primary care clinics. ${ }^{41}$ Specifically, they mapped a registry of patients with chronic disease to identify the geographical location of their patients with diabetes. They also assessed the association of community-level socioeconomic status with glucose and lipid control and found that low-income neighbourhoods had less controlled diabetes than high-income neighbourhoods, but found no association between lipid control and neighbourhood socioeconomic status. Xie et al, described a use case for identifying hot and cold spots for asthma exacerbations with the goal of providing clinicians with information to assist with development of targeted interventions. ${ }^{42}$ Buckingham describes using community-level factors together with EHR data for prevalence identification of areas with a higher percentage of patients with high body mass index, diabetes and/or other issues to develop clinic-led interventions to target those issues in certain neighbourhoods. ${ }^{22}$

Connecting community-level factors and EHR data helps researchers and providers gain a better understanding of both the clinical and non-clinical factors that contribute to disease. Without the combination of these data, one does not get the whole picture of patients, patient populations and the factors contributing to or impeding their health. For example, researchers used EHR data to compute cardiovascular health scores for patients and link them to census-tract level per capita expenditures on various food groups and sociodemographic data. In this study, they found high community-level fruit and vegetable expenditures and high income were associated with high cardiovascular health scores. ${ }^{43}$ In another study, body mass index was derived from EHR data and linked to zip-code level population characteristics. Here, researchers found lower odds of obesity were associated with zip codes that had high numbers of farmers' markets, grocery stores and college graduates. ${ }^{44}$ Drewnowski et $a t^{45}$ used EHR data to identify patients with diabetes and linked these data with socioeconomic measures from the 2000 census. They found areas with high levels of college education, property values and income were negatively associated with having diabetes. Several studies also used geocoded patient and census data to understand healthcare need by mapping federal medical services areas with actual access and utilisation. ${ }^{32} 3346$
These publications highlight the work that has been done to date, yet none of them assessed the actual impact of the targeted interventions.

Does linking community-level factors to EHR data in the primary care setting have an impact on healthcare services, patient health and health equity?

Lindau et $a l^{47}$ describe a unique community-primary care partnership that enabled infrastructure for providers to 'e-prescribe' community resources from infrastructure linked to their EHR systems. In this example, an inventory of health-promoting resources and community social service providers was developed, integrated and made available to the care team at the point of care where a prescription to social services tailored to an individual patient's needs and location could be generated. This study found collecting community resource information, creating and implementing a system within the EHR for prescribing these resources, and providing this information to patients was possible and useful. Specifically, the project provided prescriptions to 113295 patients; from those surveyed $(n=458), 19 \%$ reported they followed through on the information received. Thus, the authors concluded that the partnership and tools provided 'a powerful tool for communicating health-promoting information to a targeted population'. ${ }^{47}$

Miranda $e t a t^{25}$ describe a geographical health information system which provided public health and healthcare providers a common window into relevant data to improve health for patients and communities. One of the case studies presented in this article created a map that modelled areas with high lead exposure risk based on clinic blood lead screening data and census data. The health department used this information to target lead screening and reported an increase in capturing elevated levels without additional cost and allowed for monitoring progress in elimination of lead exposure.

These early examples demonstrate the feasibility of using community-level factors and EHR data and establishing partnerships between healthcare and community organisations; however, they did not quantify the impact of these data on improved healthcare, patient health or health equity. In our extensive review, we did not find any publications that documented the effectiveness of these types of interventions. Therefore, there are many opportunities for future research in this nascent area of study. It is also important to note that we did not find any publications reporting that the use of community-level factors and EHR data have negative impacts or do not improve on healthcare and health outcomes.

\section{CONCLUSION}

Linkages between publicly available community-level factors and EHR data have the potential to help primary care inform clinical care, target interventions, track population health and spark community partnerships with the goal of reducing health disparities and improving health 
equity. Community-level factors can provide additional contextualisation for EHR data, and the unique addition of non-clinical and clinical data can provide information on geographical clustering of disease that neither type of data can provide on its own. Although there is great enthusiasm and potential for using these data to inform primary care, there is little evidence of improved healthcare, patient health or health equity. Given our growing understanding of the multiple determinants of health, and the importance of neighbourhoods in promoting or challenging health and contributing to health disparities, we encourage primary care providers to integrate community context into their EHR data systems and use the information for patient care, population health and advocacy. DeVoe et $a t^{24}$ outlined the following steps to move the use of community-level factors in primary care forward: systematic collection and organisation of community-level data, presentation of these data to primary care providers in the healthcare setting and automated EHR actions to help meaningfully use the data. Importantly, they recommend research to determine whether these data are improving health outcomes. Indeed, we also identified an exciting nascent area of inquiry where more research is needed to quantify the benefits of incorporating and using community-level data in primary care settings to improve healthcare, health outcomes and health equity for patients and communities.

\section{SIGNIFICANCE}

There is great enthusiasm and potential for using linked publicly available community-level factors and EHR data to inform primary care practice. Community-level factors can provide additional context to patient care. The unique addition of non-clinical to clinical data can inform care, target interventions, track population health and spark community partnerships with the goal of reducing health disparities and improving health equity. Currently, there is little evidence that combining non-clinical and clinical data improves healthcare, patient health or health equity. Thus, there remains an exciting nascent area of inquiry where more research is needed to quantify the benefits of incorporating and using community-level data in primary care settings to improve healthcare, health outcomes and health equity for patients and communities.

Contributors HA was responsible for conceptualisation, methodology, investigation, writing, original draft preparation and project administration. EAJ was responsible for conceptualisation, writing, review and editing, and supervision. $\mathrm{NH}$ was responsible for conceptualisation, writing, review and editing. SL-A was responsible for writing, review and editing. SR was responsible for writing, review and editing. JEDV was responsible for conceptualisation, resources, supervision, writing, review and editing, and funding acquisition.

Funding This study was funded by Pisacano Leadership Foundation.

Competing interests None declared.

Patient consent Not required.

Provenance and peer review Commissioned; internally peer reviewed.

Open access This is an open access article distributed in accordance with the Creative Commons Attribution Non Commercial (CC BY-NC 4.0) license, which permits others to distribute, remix, adapt, build upon this work non-commercially, and license their derivative works on different terms, provided the original work is properly cited, appropriate credit is given, any changes made indicated, and the use is non-commercial. See: http://creativecommons.org/licenses/by-nc/4.0

\section{REFERENCES}

1. Diez Roux AV, Mair C. Neighborhoods and health. Ann N Y Acad Sci 2010;1186:125-45.

2. Pickett KE, Pearl M. Multilevel analyses of neighbourhood socioeconomic context and health outcomes: a critical review. $J$ Epidemiol Community Health 2001;55:111-22.

3. Robert Wood Johnson Foundation. Where we live matters for our health: neighbhorhoods and health, 2008.

4. Nelson K, Schwartz G, Hernandez S. The association between neighborhood environment and mortality: results from a national study of veterans. J Gen Intern Med 2017;32:416-22.

5. Strachan E, Duncan G, Horn E, et al. Neighborhood deprivation and depression in adult twins: genetics and genexenvironment interaction. Psychol Med 2017;47:627-38.

6. Singh GK, Siahpush M, Kogan MD, et al. built environments, and childhood obesity. Health Aff 2010;29:503-12.

7. Mobley LR, Root ED, Finkelstein EA, et al. Environment, obesity, and cardiovascular disease risk in low-income women. Am J Prev Med 2006;30:327-32.

8. Mujahid MS, Diez Roux AV, Morenoff JD, et al. Neighborhood characteristics and hypertension. Epidemiology 2008;19:590-8.

9. Haas JS, Phillips KA, Sonneborn D, et al. Variation in access to health care for different racial/ethnic groups by the racial/ethnic composition of an individual's county of residence. Med Care 2004;42:707-14.

10. Kirby JB, Kaneda T. Neighborhood socioeconomic disadvantage and access to health care. J Health Soc Behav 2005;46:15-31.

11. Schootman M, Jeffe DB, Baker EA, et al. Effect of area poverty rate on cancer screening across US communities. J Epidemiol Community Health 2006;60:202-7.

12. Schlundt DG, Hargreaves MK, McClellan L. Geographic clustering of obesity, diabetes, and hypertension in Nashville, Tennessee. J Ambul Care Manage 2006;29:125-32.

13. U. S. Department of Health and Human Services. Healthy people 2010. 2000. 2nd edn. Washington, DC: US Government Printing Office, 2010.

14. Williams DR, Costa MV, Odunlami AO, et al. Moving upstream: how interventions that address the social determinants of health can improve health and reduce disparities. J Public Health Manag Pract 2008;14(Suppl):S8-17.

15. Farley ES, Boisseau V, Froom J. An integrated medical record and data system for primary care. Part 5: Implications of filing family folders by area of residence. J Fam Pract 1977;5:427-32.

16. Kark JD, Abramson JH. Sidney Kark's contributions to epidemiology and community medicine. Int J Epidemiol 2003;32:882-4.

17. Krieger N. Overcoming the absence of socioeconomic data in medical records: validation and application of a census-based methodology. Am J Public Health 1992;82:703-10.

18. Bazemore AW, Cottrell EK, Gold R, et al. "Community vital signs": incorporating geocoded social determinants into electronic records to promote patient and population health. J Am Med Inform Assoc 2016;23:407-12.

19. Institute of Medicine. Capturing social and behavioral domains and measures in electronic health records: phase 2. Washington, DC: The National Academies Press, 2014.

20. Council on Community Pediatrics. Committee on native american child health. policy statement-health equity and children's rights. Pediatrics 2010;125:838-49.

21. Troseth MR. American academy of nursing endorses social behavioral determinants of health in electronic health records. Comput Inform Nurs 2017;35:329-30.

22. Buckingham WR. The potential and pitfalls of geocoding electronic health records. WMJ 2012;111:107-11.

23. Hughes LS, Phillips RL, DeVoe JE, et al. Community vital signs: taking the pulse of the community while caring for patients. J Am Board Fam Med 2016;29:419-22.

24. DeVoe JE, Bazemore AW, Cottrell EK, et al. Perspectives in primary care: a conceptual framework and path for integrating social determinants of health into primary care practice. Ann Fam Med 2016;14:104-8.

25. Miranda ML, Ferranti J, Strauss B, et al. Geographic health information systems: a platform to support the 'Triple Aim'. Health Aff 2013;32:1608-15. 
26. Comer KF, Grannis S, Dixon BE, et al. Incorporating geospatial capacity within clinical data systems to address social determinants of health. Public Health Rep 2011;126(3_ suppl):54-61.

27. Remington PL, Wadland WC. Connecting the dots: bridging patient and population health data systems. Am J Prev Med 2015;48:213-4.

28. Beck AF, Sandel MT, Ryan PH, et al. Mapping neighborhood health geomarkers to clinical care decisions to promote equity in child health. Health Aff 2017;36:999-1005.

29. Quiñones AR, Talavera GA, Castañeda SF, et al. Interventions that reach into communities--promising directions for reducing racial and ethnic disparities in healthcare. J Racial Ethn Health Disparities 2015;2:336-40.

30. Simpson CL, Novak LL. Place matters: the problems and possibilities of spatial data in electronic health records. AMIA Annu Symp Proc 2013;2013:1303-11.

31. Bazemore A, Phillips RL, Miyoshi T. Harnessing Geographic Information Systems (GIS) to enable community-oriented primary care. J Am Board Fam Med 2010;23:22-31.

32. Phillips RL, Kinman EL, Schnitzer PG, et al. Using geographic information systems to understand health care access. Arch Fam Med 2000;9:971-8.

33. Soares N, Dewalle J, Marsh B. Utilizing patient geographic information system data to plan telemedicine service locations. J Am Med Inform Assoc 2017;24:891-6.

34. Gottlieb LM, Tirozzi KJ, Manchanda R, et al. Moving electronic medical records upstream: incorporating social determinants of health. Am J Prev Med 2015;48:215-8.

35. Marmot M. The health gap: doctors and the social determinants of health. Scand J Public Health 2017;45:686-93.

36. Thomas S. Doctors for health equity, 2016.

37. Henize AW, Beck AF, Klein MD, et al. A road map to address the social determinants of health through community collaboration. Pediatrics 2015;136:e993-e1001.
38. Gottlieb L, Tobey R, Cantor J, et al. Integrating social and medical data to improve population health: opportunities and barriers. Health Aff 2016;35:2116-23.

39. Phillips RL, Liaw W, Crampton P, et al. How other countries use deprivation indices-and why the united states desperately needs one. Health Aff 2016;35:1991-8.

40. Angier $\mathrm{H}$, Likumahuwa $\mathrm{S}$, Finnegan $\mathrm{S}$, et al. Using geographic information systems (GIS) to identify communities in need of health insurance outreach: an OCHIN practice-based research network (PBRN) report. J Am Board Fam Med 2014;27:804-10.

41. Geraghty EM, Balsbaugh T, Nuovo J, et al. Using Geographic Information Systems (GIS) to assess outcome disparities in patients with type 2 diabetes and hyperlipidemia. The Journal of the American Board of Family Medicine 2010;23:88-96.

42. Xie S, Greenblatt R, Levy MZ, et al. Enhancing electronic health record data with geospatial information. AMIA Jt Summits Trans/ Sci Proc 2017;2017:123-32.

43. Roth C, Payne PRO, Weier RC, et al. The geographic distribution of cardiovascular health in the stroke prevention in healthcare delivery environments (SPHERE) study. J Biomed Inform 2016;60:95-103.

44. Roth C, Foraker RE, Payne PRO, et al. Community-level determinants of obesity: harnessing the power of electronic health records for retrospective data analysis. BMC Med Inform Decis Mak $2014 ; 14: 36$

45. Drewnowski A, Rehm CD, Moudon AV, et al. The geography of diabetes by census tract in a large sample of insured adults in King County, Washington, 2005-2006. Prev Chronic Dis 2014;11:E125.

46. Butler DC, Petterson S, Phillips RL, et al. Measures of social deprivation that predict health care access and need within a rational area of primary care service delivery. Health Serv Res 2013;48(2 Pt 1):539-59.

47. Lindau ST, Makelarski J, Abramsohn E, et al. Communityrx: a population health improvement innovation that connects clinics to communities. Health Aff 2016;35:2020-9. 